\title{
Genetic diversity among major endemic strains of Leptospira interrogans in China
}

\author{
Ping $\mathrm{He}^{\dagger 1}$, Yue-Ying Sheng ${ }^{\dagger}$, Yao-Zhou Shi ${ }^{2}$, Xiu-Gao Jiang ${ }^{3}$, Jin-Hong Qin ${ }^{1}$, \\ Zhi-Ming Zhang2, Guo-Ping Zhao*2,4 and Xiao-Kui Guo*1
}

Address: ${ }^{1}$ Department of Microbiology and Parasitology, Shanghai Jiao Tong University School of Medicine, Shanghai 200025, China, ${ }^{2}$ National Engineering Center for Biochip at Shanghai, Zhangjiang High Tech Park, Shanghai 201203, China, ${ }^{3}$ National Institute for Communicable Disease Control and Prevention, Chinese Center for Disease Control and Prevention (ICDC, CCDC), Beijing 102206, China and ${ }^{4}$ State Key Laboratory for Disease and Health Genomics, Chinese National Human Genome Center at Shanghai, Zhangjiang High Tech Park, Shanghai 201203, China

Email: Ping He - hpatsh@sjtu.edu.cn; Yue-Ying Sheng - kyq_1108@hotmail.com; Yao-Zhou Shi - yaozhou_shi@shbiochip.com; XiuGao Jiang - xkguo@shsmu.edu.cn; Jin-Hong Qin - jinhongq@hotmail.com; Zhi-Ming Zhang - zhimzhang@hotmail.com; Guo-

Ping Zhao* - gpzhao@sibs.ac.cn; Xiao-Kui Guo* - microbiology@sjtu.edu.cn

* Corresponding authors †Equal contributors

Published: I July 2007

BMC Genomics 2007, 8:204
Received: 8 March 2007

Accepted: I July 2007

(c) 2007 He et al; licensee BioMed Central Ltd.

This is an Open Access article distributed under the terms of the Creative Commons Attribution License (http://creativecommons.org/licenses/by/2.0), which permits unrestricted use, distribution, and reproduction in any medium, provided the original work is properly cited.

\begin{abstract}
Background: Leptospirosis is a world-widely distributed zoonosis. Humans become infected via exposure to pathogenic Leptospira spp. from contaminated water or soil. The availability of genomic sequences of Leptospira interrogans serovar Lai and serovar Copenhageni opened up opportunities to identify genetic diversity among different pathogenic strains of $L$. interrogans representing various kinds of serotypes (serogroups and serovars).
\end{abstract}

Results: Comparative genomic hybridization $(\mathrm{CGH})$ analysis was used to compare the gene content of $L$. interrogans serovar Lai strain Lai with that of other $10 \mathrm{~L}$. interrogans strains prevailed in China and one identified from Brazil using a microarray spotted with 3,528 protein coding sequences (CDSs) of strain Lai. The cutoff ratio of sample/reference (S/R) hybridization for detecting the absence of genes from one tested strain was set by comparing the ratio of $S / R$ hybridization and the in silico sequence similarities of strain Lai and serovar Copenhageni strain Fiocruz LI-I30. Among the II strains tested, 275 CDSs were found absent from at least one strain. The common backbone of the $L$. interrogans genome was estimated to contain about 2,917 CDSs. The genes encoding fundamental cellular functions such as translation, energy production and conversion were conserved. While strain-specific genes include those that encode proteins related to either cell surface structures or carbohydrate transport and metabolism. We also found two genomic islands (Gls) in strain Lai containing genes divergently absent in other strains. Because genes encoding proteins with potential pathogenic functions are located within Gls, these elements might contribute to the variations in disease manifestation. Differences in genes involved in O-antigen biosynthesis were also identified for strains belonging to different serogroups, which offers an opportunity for future development of genomic typing tools for serological classification.

Conclusion: $\mathrm{CGH}$ analyses for pathogenic leptospiral strains prevailed in China against the $L$. interrogans serovar Lai strain Lai CDS-spotted microarrays revealed 2,917 common backbone CDSs and strain specific genes encoding proteins mainly related to cell surface structures and carbohydrated transport/metabolism. Of the $275 \mathrm{CDSs}$ considered absent from at least one of the $L$. interrogans strains tested, most of them were clustered in the rfb gene cluster and two putative genomic islands (GI A and B) in strain Lai. The strain-specific genes detected via this work will provide a knowledge base for further investigating the pathogenesis of $L$ interrogans and/or for the development of effective vaccines and/or diagnostic tools. 


\section{Background}

The genus Leptospira comprises a heterogeneous group of saprophytic and pathogenic species belonging to the order Spirochaetales [1]. Pathogenic Leptospira spp., including L. interrogans, L. kirschneri, L. noguchii, L. borgpetersenii, L. santarosai, L. weilii, and etc. [2], are etiological agents of leptospirosis. They are excreted in urine of the infected animals and may penetrate the human body through skin or mucous membranes when the host contacts with contaminated water or soil [3]. Because of the wide spectrum of animal species that serve as reservoirs, leptospirosis is considered the most widely spread zoonotic disease [1].

The genus Leptospira, including pathogenic and saprophytic species, can be further classified into serological types, i.e., serogroups and serovars, defined by a crossagglutination absorption test. The alternative genotypic classification is based on DNA hybridization and thus, the leptospires can be assigned to the species level [4-6]. However, these two classification systems are not always consistent. Strains belonging to the same serovar may belong to different Leptospira species and vice versa $[2,6]$.

L. interrogans serovar Lai is a virulent serovar of serogroup Icterohaemorrhagiae, which is more likely to cause severe leptospirosis than the other serovars prevailing in China [7]. Following the determination of the complete genomic sequence of the $L$. interrogans serovar Lai strain Lai (\#56601) in 2003 [8], the genome of another L. interrogans serovar Copenhageni strain Fiocruz L1-130 of the same serogroup Icterohaemorrhagiae was sequenced and released $[9,10]$. Genomic comparison of strain Lai with strain Fiocruz L1-130 revealed extensive variation in the number and distribution of insertion sequences and other genomic contents [10], which should eventually determine the unique phenotypes of each strain.

Although whole-genome sequencing is a powerful method of genetics and genomics, it is still laborious and expensive. Recently, comparative genomic hybridization (CGH) has been used to facilitate the comparison of unsequenced bacterial genomes in order to monitor the gene contents of closely related bacterial species [11-15]. Based on the genomic sequence of L. interrogans serovar Lai strain Lai, we constructed a microarray to compare the genomes of a number of L. interrogans serovars in order to clarify their genetic relationship and identify features that may serve as molecular markers to profile the serovars or genospeices, which may correspond to different levels of disease manifestation. Eleven L. interrogans strains that are endemic in China were analyzed. Sequences absent in $L$. interrogans were mostly confined to regions in the rfb gene cluster and two genomic islands (GIs) of strain Lai. The results are discussed in the context of the possible role of these regions in L. interrogans with respect to serovar determination and virulence.

\section{Results and discussion CGH microarray analysis and in silico genomic comparison of $L$. interrogans serovar Lai vs $L$. interrogans serovar Copenhageni}

The genomes of two L. interrogans strains, Lai and Fiocruz L1-130 belonging to the same serogroup Icterohaemorrhagiae, were completely sequenced in China and Brazil respectively $[8,9]$. The genomic contents of these two strains were compared by CGH employing a strain Lai sequence based whole genome CDS microarray (Methods). The genomic sequences of the two strains were also compared in silico. CDSs of strain Lai absent in Fiocruz L1130 were predicted by a BLASTN search, and the degree of similarity between the matching tested genomic sequence and the probe itself in terms of the length of match and the percentage sequence identity at the DNA level was expressed as $\mathrm{H}$ values (see Methods).

For CGH analysis with DNA microarray slides, it is important to set an appropriate threshold to detect CDSs missing from the sample strains. In this study, we compared the $\mathrm{H}$ values to the results of CGH between strain Lai and Fiocruz L1-130 expressed by the normalized signal ratio of sample strain/reference strain hybridization (S/R ratio or ratio, hereafter, Fig. 1). It is clear that the plot of $\mathrm{H}$ values of each CDS versus its corresponding $\log _{2} S / R$ ratio values was divided into two groups defined by the apparent cutoff values of $\mathrm{H}$ and the $\log _{2}$ ratio. We may define the cutoff $H$ value as 0.2 because any CDS is either absent or significantly divergent in strain Fiocruz L1-130 from that of strain Lai, when $\mathrm{H} \leq 0.2$ (total 59 CDSs, among them, 37 with $\mathrm{H}=0$, i.e., total deletion). For the same token, if the $H$ value of a CDS is larger than 0.2 , it can be considered a conserved gene. We may also draw the cutoff $\mathrm{S} / \mathrm{R}$ ratio for hybridization as $0.33(\log 2$ ratio $=-1.585)$ because this value divides the CDSs into two categories almost identical to that of $\mathrm{H}=0.2$, except two data points (two dot arrowed in Fig. 1), which is the minimum among all the other possible cutoff values (Table 2). In other words, although, for unknown reasons, there were genes with unexpected signal ratios in groups IV and VI, the numbers of such genes were relatively low (1 of 89 genes and 1 of 313 genes) and with this cutoff, we may have the minimal $3.3 \%$ false positives $(2 / 61)$ and zero false negatives (0/3131) among all the other choices (refer to Table 2).

An S/R ratio of -1 on the $\log _{2}$ scale was frequently used in previous studies $[11,15]$. However, for this study, with the threshold value of -1 , four conserved genes with $H$ value more than 0.9 would be designated as absent in strain Fiocruz L1-130. Therefore, a threshold $\log _{2}$ ratio value of - 


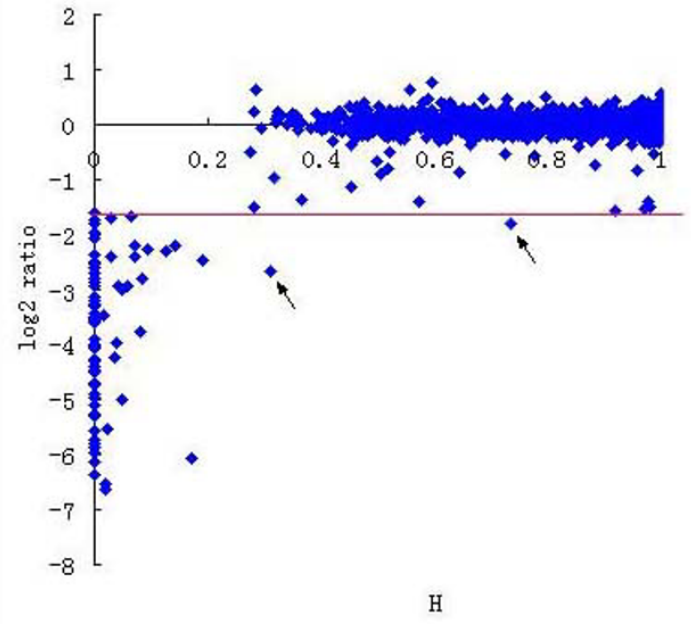

Figure I

The correlation of the level of sequence similarity determined by BLASTN ( $\mathrm{H}$ values) and the degree of chromosomal DNA hybridization determined by microarray CGH analysis ( $\log _{2} S / R$ ratio) between $L$. interrogans strain Lai and Fiocruz LI-I30. Blue dot indicates the each CDS's $\mathrm{H}$ value and its corresponding $\log _{2}$ ratio $(\mathrm{S} / \mathrm{R})$; red line indicates the cutoff ratio ( $\log _{2} \mathrm{~S} / \mathrm{R}$ ratio), which is -1.585 .

$1.585(\mathrm{~S} / \mathrm{R}$ ratio $=0.33)$ determined by the statistical correlation between the $S / R$ ratio and the genomic sequence similarity (H value) of L. interrogans strain Lai and strain Fiocruz L1-130 is more appropriate than the artificial value of - 1 for detecting the absent/divergent CDSs for the L. interrogans strain Lai whole genome CDS microarray-based CGH studies.

\section{Overview of the microarray analysis}

The genomic contents of the $11 \mathrm{~L}$. interrogans strains were analyzed by CGH using the CDSs encoded by the genome of strain Lai as reference. The results are shown in Fig. 2 and Additional file 1 . Of the 3,528 CDSs spotted on the microarray slides, 275 were considered absent from at least one of the L. interrogans strains tested. These CDSs accounted for $5.8 \%$ of all the CDSs of strain Lai annotated [8] or $7.9 \%$ of the CDSs spotted on the slides. With invalid data excluded (Methods), the remaining 2,917 CDSs were likely conserved in all the strains used in this study. There were differences in the numbers of absent CDSs for different strains, ranging from 61 in strain Fiocruz L1-130 to 161 in strain P7 (Table 1).
Sixteen of the 275 absent CDSs were chosen for confirmation tests with PCR amplification in $12 \mathrm{~L}$. interrogans strains. Only 4 reaction results did not match the CGH results among the 192 PCR reactions. Moreover, we also validated the CGH results by comparing them to the publicly available sequence variation data of the $\mathrm{rfb}$ loci from five serovars of L. interrogans (Canicola, Pyrogenes, Autumnalis, Australis and Pomona) [16] employing the BLASTN in silico hybridization method. The two results were well matched and in conclusion, our CGH results are reliable and reasonable.

The distribution of the absent genes indicated that majority of the absent/divergent genes were clustered in three regions (Fig. 2). The $r f b$ gene cluster (from LA1576 to LA1672) was previously described [8]. The other two regions were referred as GI A (from LA0702 to LA0717) and GI B (from LA1747 to LA1851) respectively. The rest absent genes were scattered over the genome.

The proportions of the absent CDSs with respect to their functional category are shown in Table 3. Genes encoding fundamental cellular functions were relatively conserved (absent genes only counted less than 5\% of the corresponding categories), such as translation (2.82\%), energy production and conversion $(1.31 \%$, the lowest rate of gene absent for all categories), as well as transport and metabolism for lipid and inorganic ions (both less than $2 \%$ ). In contrast, genes in 5 functional categories including cell cycle control and defense mechanisms have over $10 \%$ of the CDSs absent. Approximately $16.53 \%$ of the genes assigned to cell wall biogenesis including sugar biosynthetic enzymes and outer membrane efflux proteins were absent from most of the L. interrogans strains analyzed. Approximately $13.19 \%$ of the genes assigned to carbohydrate transport and metabolism and 14.52\% of those assigned to secondary metabolites biosynthesis, transport and catabolism were also missing. One must clarify that genes of the last category mainly encode methyltransferases, which are likely involved in sugar modification. Thus, it is not surprising that most of the absent genes in these three categories ( $82 \%$ absent genes of cell wall biogenesis, 95\% absent genes of carbohydrate transport and metabolism and 78\% absent genes of secondary metabolite biosynthesis, transport and catabolism) were located in the O-antigen $(r f b)$ locus.

\section{Structure and function of the genomic islands}

Three bacteriophages of the saprophytic L. biflexa were first isolated by Saint Girons et al. [17]. These bacteriophages do not infect representative species of pathogenic leptospires. However, evidence for horizontal transfer of DNA among L. interrogans (sensu lato) came from studies of the intervening sequences found within the 23S rRNA gene [18] and from the finding that the leptospiral 
Table 2: Distribution of the sample/reference (S/R) signal ratios of strain Lai CDSs hybridized to the chromosomal DNA of Fiocruz LI130 by $\mathrm{H}$ values derived from in silico DNA sequence similarity comparison of the two strains*

\begin{tabular}{|c|c|c|c|c|}
\hline \multirow[t]{2}{*}{ Group } & \multirow[t]{2}{*}{$\mathrm{H}$ value } & \multirow[t]{2}{*}{ No. of CDSs in DNA array } & \multicolumn{2}{|c|}{ No. of CDSs at a S/R ratio of: } \\
\hline & & & $\leq 0.33$ & $>0.33$ \\
\hline 1 & $\geq 0$ and $<0.1$ & 55 & 55 & 0 \\
\hline ॥ & $\geq 0.1$ and $<0.2$ & 4 & 4 & 0 \\
\hline III & $\geq 0.2$ and $<0.3$ & 4 & 0 & 4 \\
\hline IV & $\geq 0.3$ and $<0.5$ & 89 & 1 & 88 \\
\hline $\mathrm{V}$ & $\geq 0.5$ and $<0.7$ & 246 & 0 & 246 \\
\hline VI & $\geq 0.7$ and $<0.9$ & 313 & 1 & 312 \\
\hline VII & $\geq 0.9$ and $\leq 1$ & 2481 & 0 & 2481 \\
\hline Total & $\geq 0$ and $\leq 1$ & 3192 & 61 & $313 \mid$ \\
\hline
\end{tabular}

* Among the total of 3528 CDSs array, there were 336 invalid data for low quality signal of hybridyzation derived from all of the CGH experiments.

That makes the total 3192 CDSs listed in the table.

lipopolysaccharide biosynthetic locus $(r f b)$ is located in a genomic island that was probably acquired through horizontal transfer from gram-negative source(s) $[19,20]$.

Three regions with large sets of missing CDSs detected by CGH in the $11 \mathrm{~L}$. interrogans strains presented some characteristics of laterally transferred genomic elements. Besides the $r f b$ gene cluster, the GC content, genome signature, as well as the codon and amino acid usage bias of the other two missing regions were analyzed along with the chromosomal DNA sequence of strain Lai (Fig. 3) [21] to verify their GI characteristics.

The first putative genomic island (GI A) is a 28-kb-long segment of DNA encompassing CDSs from LA0702 to LA0717. It begins with an insertion sequence ISlin 1 and a transposase (LA0702) [9], and ends with an IS3 and a transposase gene (LA0717) [9]. This region presents many characteristics expected for a typical GI [21-23]: (1) higher GC content, (2) altered codon preference, (3) different amino acid usage pattern, and (4) genes encoding transposases at the ends (CDSs LA0702 and LA0717).

Among the 16 CDSs included in this region, there are 8 CDSs without any significant homology to genes in the GenBank database. Besides the 2 proximal genes both encoding transposases, there are 4 other genes encoding a transposase, an integrase, a molybdate metabolism regulator and a lipoprotein, respectively.

There are two genes likely related to pathogenesis. LA0705 was found to contain an LRR (Leucine-rich repeats), which is characteristic for a diverse array of proteins providing a versatile framework for protein-protein interaction [24]. It is particularly interesting to notice that, all of the bacterial LRR proteins that have been well character- ized so far, including those from Listeria monocytogenes [25], Streptococcus [26], Yersinia pestis [27], Salmonella typhimurium [28] and Shigella flexneri [29], are implicated in virulence. It was shown to be a major virulence factor in $L$. monocytogenes presumably functioning as triggering engulfment of the bacterium after specifically interacting with cell-surface receptors [25]. On the basis of their sequence similarity, the probable pathogenic function of this gene in $L$. interrogans serovar Lai is worth to be further explored.

Another CDS, LA0706, shares amino acid homology with hemin receptor of gram-negative bacteria involved in the acquisition of iron from hemin and hemoglobin, such as the ChuA of Escherichia coli O157:H7 [30], HemR of Yersinia enterocolitica [31], ShuA of Shigella dysenteriae [32], and HgpB of H. influenzae [33]. Its contribution to bacterial virulence was proven in uropathogenic E. coli[34] and the heme scavenging function of the hemin receptor ChuA is speculated to depend on the activity of $\alpha$-hemolysin, which gains access to the intracellular heme reservoir [35]. Since 9 hemolysins were confirmed in strain Lai $[36,37]$, one may speculate that the coupling of hemolysis with heme utilization could serve as an effective iron acquisition strategy during the progression of strain Lai infection.

The second large GI (GI B) spans almost $83 \mathrm{~kb}$, from LA1747 to LA1851. It is not inserted at the 3 ' end of a tRNA gene and it bears no significant variations in its GC content. However, it does have all the expected properties of a typical GI in other aspects. It begins with an insertion element IS1501 and a transposase [9], and ends with a transposase. This island also has large numbers of CDSs encoding proteins with unknown functions, but several of others are homologous to the bacteriophage-encoded 


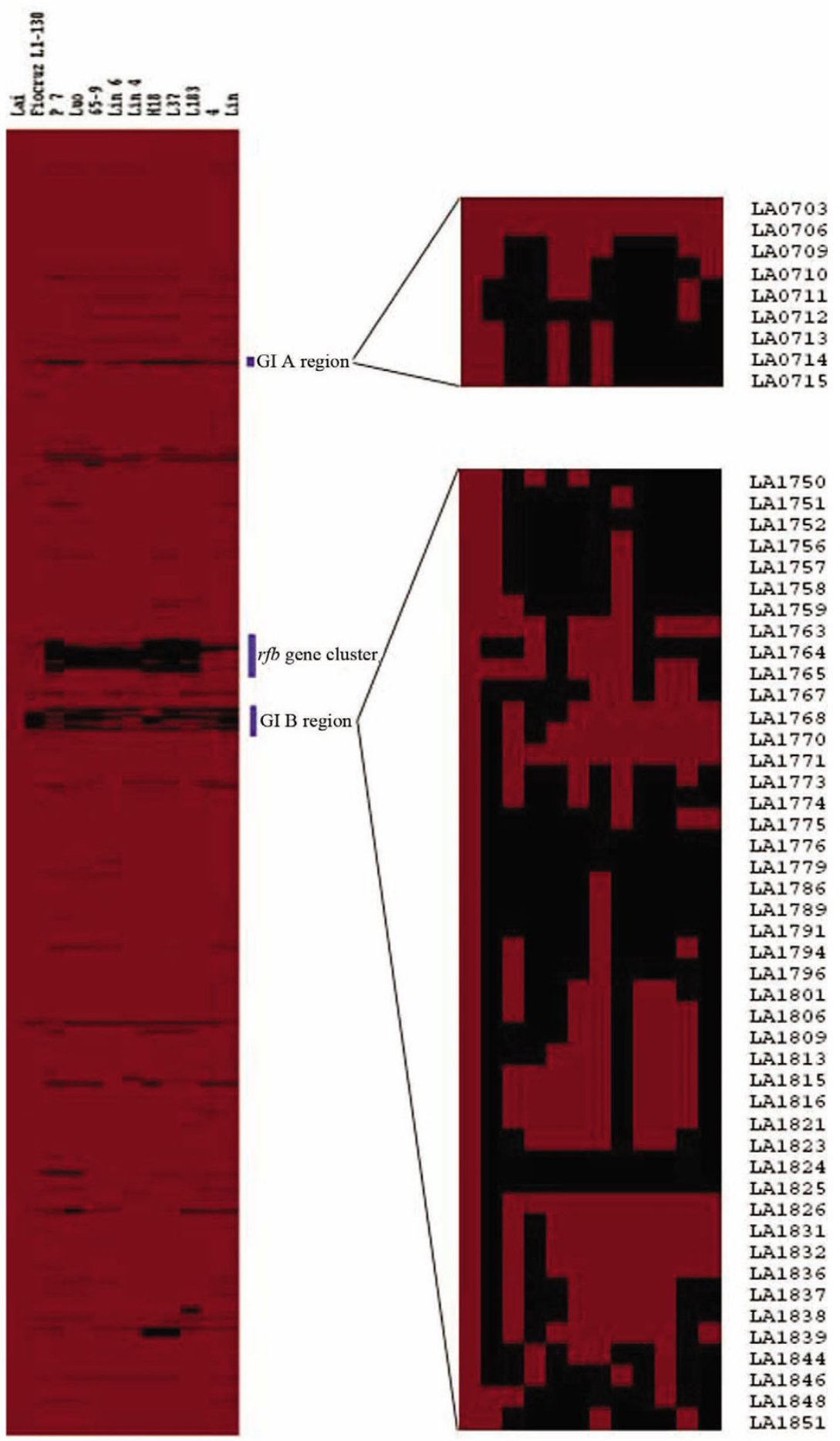

\section{Figure 2}

Genetic diversity of $L$. interrogans strains detected by microarray CGH analysis. Red and black areas denote the genes that are present/conserved and absent/divergent respectively, and the genes are arranged in order of LA and LB numbers from LA000I at the top to LB367 at the bottom. The columns represent the strains analyzed and are labeled on top of the left panel. Blue bars indicate the $r f b$ locus and two Gl regions. Zoomed images of the right panel represent the two genomic island-like regions: $\mathrm{Gl} \mathrm{A}$ and $\mathrm{Gl} B$ region. The genes in these regions are defined by their LA numbers. 
Table I: Bacterial strains used in this study and number of absent CDSs in each strain detected by CGH

\begin{tabular}{|c|c|c|c|c|c|}
\hline Serogroup & Serovar & Strain & Source & Source-Animal & No. of absent CDSs \\
\hline Icterohaemorrhagiae & Lai & Lai & Sichuan Province, China & Human & 0 \\
\hline Canicola & Canicola & Lin & Guangdong Province, China & Human & 110 \\
\hline Pyrogenes & Pyrogenes & 4 & Guangdong Province, China & Human & 90 \\
\hline Autumnalis & Autumnalis & Lin 4 & Zhejiang Province, China & Human & 98 \\
\hline Australis & Australis & $65-9$ & Fujian Province, China & Horse & 122 \\
\hline Pomona & Pomona & Luo & Fujian Province, China & Human & $|5|$ \\
\hline Grippotyphosa & Linhai & $\operatorname{Lin} 6$ & Zhejiang Province, China & Human & 98 \\
\hline Hebdomadis & Hebdomadis & P 7 & Sichuan Province, China & Human & 161 \\
\hline Bataviae & Paidjan & L 37 & Guangxi Province, China & Human & 159 \\
\hline Sejroe & Wolffi & L 183 & Yunnan Province, China & Human & 137 \\
\hline Sejroe & Haemolytica & $\mathrm{H} 18$ & Yunnan Province, China & Human & 144 \\
\hline Icterohaemorrhagiae & Copenhageni & Fiocruz LI - I 30 & Salvador, Brazil & Human & 61 \\
\hline
\end{tabular}

proteins (LA1833, LA1835 and LA1836) and integrases (LA1768 and LA1811). This indicates that phage-mediated integration events may be involved in the acquisition of this island.

Of the 45 CDSs in the GI B region spotted on the microarray, majority of them were missing from the strains tested (Fig. 2). The pattern of the absent genes seemed highly mosaic. Further concerning the very low level of variation in its GC content and the presence of multiple transposases, it may suggest that the GI B region is likely a site experienced extensive insertion, excision and recombination and it could be acquired from species with $\mathrm{G}+\mathrm{C}$ content similar to that of L. interrogans or that the base composition of the acquired DNA have gradually adapted to the host genome.

It is particularly interesting that Fiocruz L1-130 lacks the whole GI B segment except 11 genes located at the two ends of this region. This missing region covers a 54-kb DNA segment specific to strain Lai (from LA1768 to LA1847) [10]. Recently, Bourhy and his colleagues named this 54-kb DNA region LaiGI I and demonstrated it can be excised from the chromosome to form a replicative plasmid [38]. They also observed imprecise excision of LaiGI I in L. interrogans serovar Lai. This finding may further support the mosaic character of the GI $\mathrm{B}$ region detected in different strains of L. interrogans, which is larger than and covers the whole segment of LaiGI I.

The GI B also contains genes encoding putative regulators. For example, the AraC family transcriptional regulator gene (LA1770) has been shown to regulate diverse bacterial functions including sugar catabolism, response to stress and virulence [39-43].

Horizontal gene transfer plays an important role in the evolution of different bacterial pathotypes [22]. The two putative GIs found in strain Lai contained many divergent genes with several features of pathogenicity and metabolic islands. Because these GIs are largely missing in other pathogenic $L$. interrogans spp., they may not encode genes essential for pathogenesis but might contribute, to certain extent, the severe pathogenic properties of serovar Lai infection [7].

\section{Structure and function of the rfb gene cluster}

Leptospiral LPS plays critical roles in both pathology and immunity during the course of leptospirosis and forms the basis for serological classification of Leptospira spp. [1,44-46]. The O-antigens are synthesized by a set of enzymes encoded by the $r f b$ gene cluster in addition to a few genes scattered over the whole chromosome [8]. The nucleotide sequence of the strain Lai $r f b$ locus spanning LA1576- LA1672 comprises $103 \mathrm{~kb}$ [8]. CGH analysis revealed that although the $r f b$ gene cluster is frequently absent from all strains tested except Fiocruz L1-130, its 3'proximal end is conserved, which spans from LA1658 through to LA1672. In contrast, the genetic layout at the 5 '-proximal end is more variable. Because the genes located in this segment of strain Lai (and Fiocruz L1-130) were predicted to encode glycosyltransferases and enzymes catalyzing sugar activation, the genetic variations of this segment is likely to cause the variations in LPS composition/structure of the tested strains. These results confirmed previous reports that the genetic basis for serological differences among leptospiral SVs were related to the presence of specific sugar-biosynthetic or -modifying genes in their respective $r f b$ loci $[16,46]$.

In addition, comparison of the $r f b$ loci of strains Lai and Fiocruz L1-130, both belong to the same serogroup, Icterohaemorrhagiae, revealed only minor gene diversity. Hierarchical clustering of the CGH data based on the 89 $r f b$ genes further revealed the phylogenetic relationship among different strains (Fig. 4). The unrooted (uneducated) tree revealed that strains Lai and Fiocruz L1-130 were clustered together but showed relatively low correla- 
Table 3: Distribution of strain Lai CDSs and CGH analysis identified absent CDSs in tested strains by functional classes

\begin{tabular}{|c|c|c|c|}
\hline Category* & No. of CDSs in strain Lai & No. of CDSs absence\# & $\%$ of absent CDSs \\
\hline Translation & 177 & 5 & 2.82 \\
\hline Transcription & 154 & 10 & 6.49 \\
\hline Replication, recombination and repair & 250 & 15 & 6.00 \\
\hline Cell cycle control, mitosis and meiosis & 63 & 8 & 12.70 \\
\hline Defense mechanisms & 51 & 6 & 11.76 \\
\hline Signal transduction mechanisms & 254 & 8 & 3.15 \\
\hline Cell wall/membrane biogenesis & 236 & 39 & 16.53 \\
\hline Cell motility & 120 & 6 & 5.00 \\
\hline Intracellular trafficking and secretion & 73 & 5 & 6.85 \\
\hline Posttranslational modification, protein turnover, chaperones & 121 & 4 & 3.31 \\
\hline Energy production and conversion & 153 & 2 & 1.31 \\
\hline Carbohydrate transport and metabolism & 144 & 19 & 13.19 \\
\hline Amino acid transport and metabolism & 218 & 7 & 3.21 \\
\hline Nucleotide transport and metabolism & 62 & 2 & 3.23 \\
\hline Coenzyme transport and metabolism & 116 & 3 & 2.59 \\
\hline Lipid transport and metabolism & 114 & 2 & 1.75 \\
\hline Inorganic ion transport and metabolism & 145 & 2 & 1.38 \\
\hline Secondary metabolites biosynthesis, transport and catabolism & 62 & 9 & 14.52 \\
\hline General function prediction only & 504 & 49 & 9.72 \\
\hline Function unknown & 228 & 15 & 6.58 \\
\hline
\end{tabular}

* Functional categories of strain Lai CDSs were based on information from the GenBank database [67].

\# Some of the CDSs were not include in any of the categories, while some other CDSs may belong to more than one category. Therefore, the sum of the absent genes for individual category does not equal to the total number of the absent CDSs

tion to other strains in this study. Interestingly, strains L183 and H18 (both belong to the same serogroup, Sejroe) were also clustered together. This result implies that the compositions of the $r f b$ locus genes from strains of the same serogroup are likely more similar to each other than those of different serogroups. Although strains belonging to different serogroups were also found to fall under the same node, such as strains 4 and Lin, and strains Lin4, Lin6 and Luo; no strains belonging to the same serogroup were separated into two or more different nodes. Due to the lack of comprehensive sequence information for the $r f b$ loci of all the strains tested, this result may lie in incapable of identifying $r f b$ genes present in the tested strain but absent from the strain Lai-based microarray.

Because of the key role of leptospiral LPS in pathology, immunity and taxonomy, the continued investigation of LPS biosynthetic genes in other serovars, particularly the strain-specific and/or missing regionsof the $r f b$ loci is important. Conserved sequences flanking missing CDSs identified by the CGH analysis for different serovar strains might serve as appropriate primer candidates for amplifying strain-specific regions, which could eventually be useful for rapid identification and isolation of characteristic genomic segments (genes or gene clusters) corresponding to leptospiral serogroups and serovars.

\section{Genes associated with immunity}

Human vaccines composed of inactivated whole bacterial cell or outer membrane envelope are available in some countries to prevent leptospirosis $[47,48]$. However various kinds of serovar specificity limited the efficacy of protection against different pathogenic leptospires $[49,50]$. A major focus of research for the prevention of leptospirosis is to identify proteins conserved among pathogenic leptospires, which may generate cross-protection against strains of various serovars [51-55]. In addition to the complete genomic sequence information for pathogenic bacteria, CGH analysis was useful as one of the approaches based on reverse vaccinology [56] for screening vaccine candidates against leptospirosis.

Genes that are highly conserved over a broad range of strains could be useful for the development of a proteinbased vaccine capable of protecting hosts against most of the pathogenic serogroups of L. interrogans in China. Our results showed that 24 putative lipoprotein or outer membrane proteins were not conserved among the strains tested [see Additional file 2]. However, previous report indicated that OmpL1 and LipL32 were highly conserved among the main endemic strains of L. interrogans in China [57]. This CGH analysis not only confirmed these results but further identified additional conserved leptospiral protein antigen candidates, such as LipL41 and immunoglobulin-like proteins, and they have been shown to elicit protective immunity in animal models [58-60].

\section{Virulence factors}

The primary lesion caused by leptospiral infection is damaging to the endothelium of small blood vessels, leading 


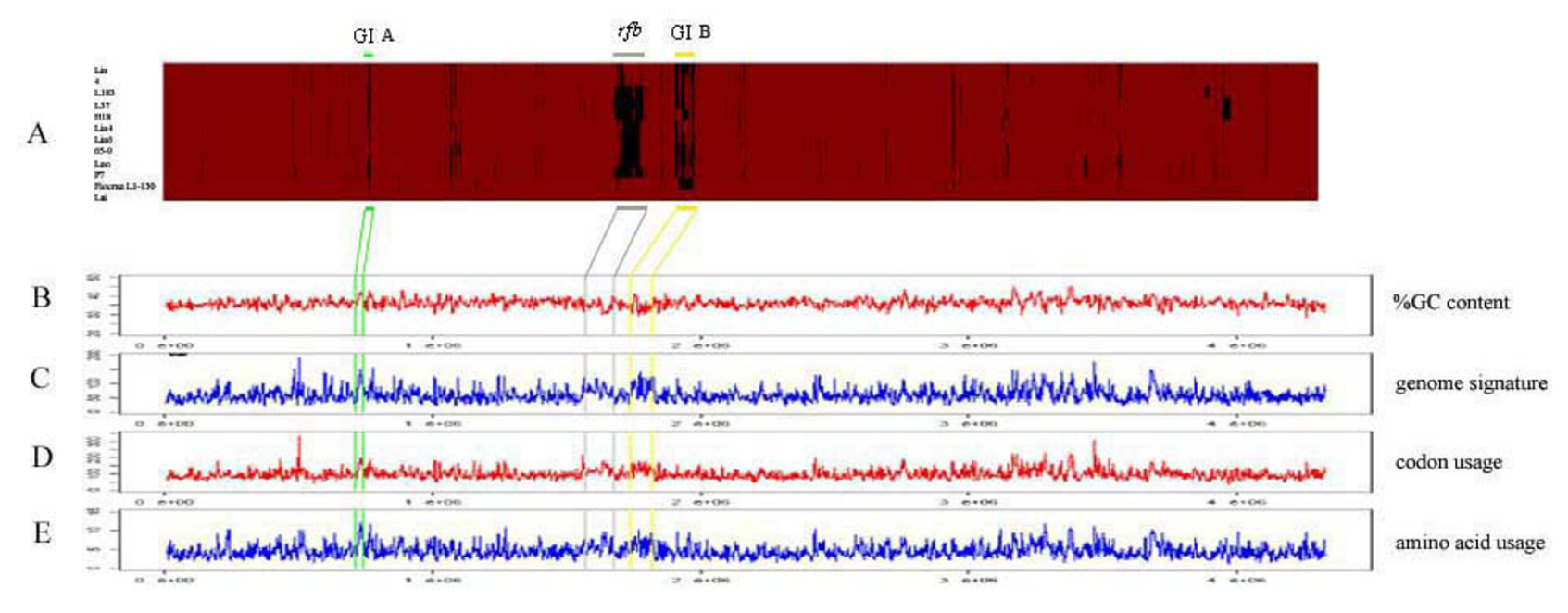

Figure 3

Comparative analysis of the diverged $L$. interrogans genomes observed by CGH with respect to their signatures defining genomic islands. (A) The presence/absence CDSs of all tested strains comparing to that of strain Lai ordered from LA000I to LB367. Red and black areas denote the presence and absence of genes respectively. The blue bar indicates the GI A region, the grey bar indicates the $r f b$ locus, and the yellow bar indicates the GI B region. These 3 regions are specifically drawn to the following sketches indicating the variations in strain Lai for properties of possible genomic islands: CG content (B), genome signature $(\mathbf{C})$, codon usage $(\mathbf{D})$, and amino acid usage (E).

to hemorrhage and localized ischemia in multiple organs [6]. Potential virulence factors such as hemolysin, protease and ankyrin-like proteins are suggested for pathogenesis of leptospirosis [10]. The CGH results showed that most of the potential virulence factors were conserved among all strains. The L. interrogans strain Lai microarray included the 7 genes coding for hemolysins [36,37], of which, 5 (LA0327, LA0378, LA1650, LA3050 and LA3937) were conserved among all strains tested. Two hemolysin genes (LA1027 and LA1029) were absent from strain 65-9. Ankyrin repeats were found in numerous proteins mediating specific protein-protein interactions [61]. Genes encoding ankyrin-like proteins were found in bacterial genomes located in close proximity to genes encoding proteins involved in either nutrient acquisition and uptake or tolerance/resistance to antibiotics, starvation or oxidative stress $[62,63]$. The microarray used for this CGH analysis included the 11 ankyrin-like protein encoding genes. These genes were conserved in all strains except LA2263, which was absent from strain 65-9. The gene encoding collagenase was also conserved in all strains tested.

\section{Conclusion}

L. interrogans serovar Lai strain Lai whole genome CDSs microarray based CGH analysis revealed extensive similarities in gene content among $L$ interrogans strains of different serovars endemic in China. We discovered that 2,917 of the 3,528 CDSs represented on the microarray were present/conserved in any of the 11 given $L$ interrogans strains. Only 275 CDSs were absent when compared to $L$ interrogans strain Lai. Most of these strain specific genes are focused on 3 genomic island-like loci. Of which, two GIs (GI A and GI B) had several features as pathogenicity and metabolic islands. Both of them contain many divergent genes, which may contribute to differences in disease manifestation. Differences in the genes involved in $\mathrm{O}$ antigen synthesis largely focused on the third genomic island-like $r f b$ locus were also identified in strains belonging to different serogroups, which will open new avenues for the development of rapid typing tools by analyzing serovar-specific genes. Although strain-specific genes may result from genetic drift, some of them are likely to encode proteins adapted to genetically diverged hosts or factors contributed to different disease outcomes. Given the small sample size and lack of clinical information for many of the strains, we cannot correlate these specific genes with particular disease outcomes. However, The strain-specific genes presented by this work will form the basis for further investigation of the pathogenesis of $L$ interrogans and will be useful for data-mining aiming at future development of effective vaccines or diagnostic means.

\section{Methods \\ Bacterial strains and culture conditions}

The L. interrogans strains used in this study are listed in Table 1. Strain Fiocruz L1-130 belongs to serovar Copen- 

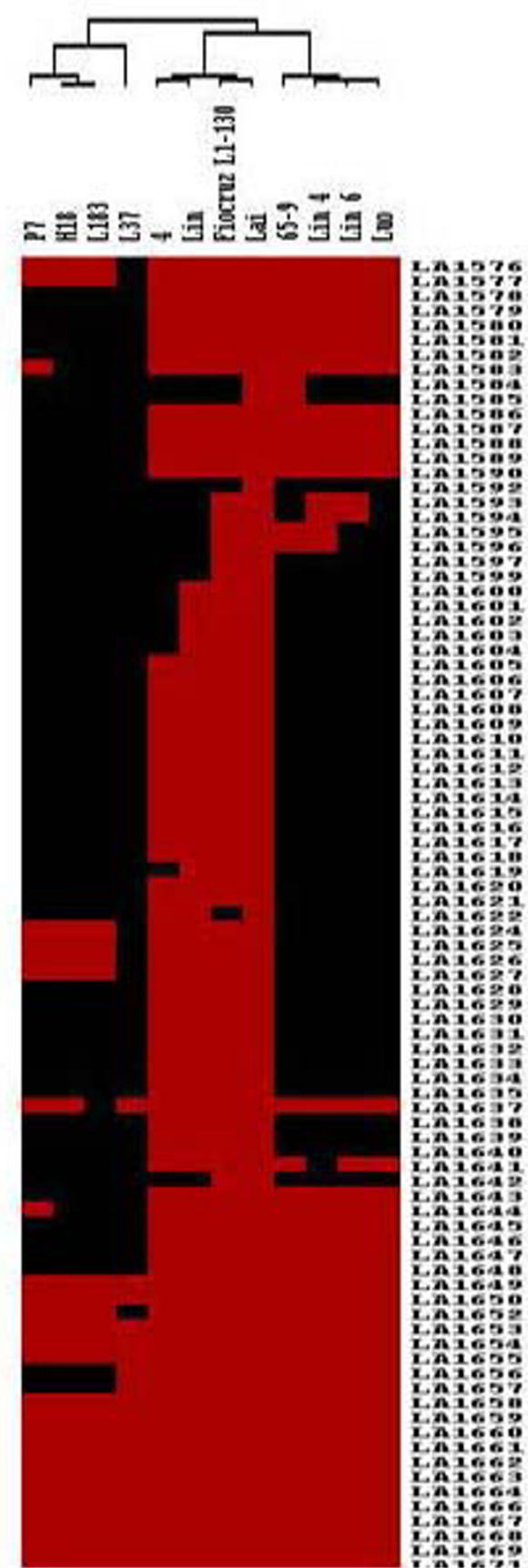

\section{Figure 4}

Cluster analysis of $L$. interrogans serovar Lai $r f b$ genes. The subset of $89 \mathrm{rfb}$ genes in microarray was used to generate a dendrogram of strains based on the presence or absence of the genes. The strains were grouped by average hierarchical clustering using the CLUSTER program and the output displayed using the TREEVIEV program. Shown at the top is the unrooted tree for the relationship of the serovars. Red and black areas denote the presence and absence of genes respectively. hageni, one of the prevalent serovars in Brazil. L. interrogans serovar Lai strain Lai was encoded \#56601 by National Institute for the Control of Pharmaceutical and Biological Products (NICPBP) of China and was maintained by the Chinese Center for Disease Control and Prevention (CCDC) with other prevalent pathogenic leptospiral strains in China, isolated from human or horse. The genomic DNA of strain Fiocruz L1-130 was kindly provided by the Centro de Pesquisas Goncalo Moniz. Strains were grown in liquid Ellinghausen-McCullough-Johnson-Harris (EMJH) medium [64] at $28^{\circ} \mathrm{C}$ under aerobic conditions and collected at a density of about $10^{8}$ bacteria per ml. Bacterial genomic DNA was purified using a Bacteria Genomic DNA kit (Huashun Co.) according to the manufacturer's instructions.

\section{Construction of $\mathrm{L}$. interrogans CDS microarray}

Annotation of the L. interrogans serovar Lai strain Lai genome identified 4727 CDSs (accession number GB: AE010300 for CI and GB: AE010301 for CII). Among them, very short CDSs (less than $250 \mathrm{bp}$ ) and CDSs highly homologous to each other at the nucleotide levels were all excluded and a total of 3,528 annotated CDSs were selected for microarray fabrication. PCR primers were designed using Primer3. All primers were synthesized by Dgbio Co. L. interrogans serovar Lai strain Lai genomic DNA was used as the template for PCR amplification. The thermal cycle parameters were $30 \mathrm{sec}$ denaturation at $94^{\circ} \mathrm{C}, 45 \mathrm{sec}$ annealing at $55^{\circ} \mathrm{C}$ and 1.5 min elongation at $72^{\circ} \mathrm{C}$ for 35 cycles. Amplified products were checked on agarose gels to verify their size and quantity, and were scored as successful if a single product of the expected mobility was detected. Amplified products were ranged from 250 to $1200 \mathrm{bp}$. The final array consisted of 3528 CDSs (74.6\% of annotated CDSs). The PCR products were then purified using 96-well Multiscreen PCR plates (Millipore) following the user manual instructions. The purified DNAs were air-dried at $65^{\circ} \mathrm{C}$, and were re-suspended in $30 \mu \mathrm{l}$ of $50 \%$ DMSO. Final concentration of the spotting sample is $250 \mathrm{ng} / \mu \mathrm{l}$.

\section{Microarray printing and processing}

The PCR products $(250 \mathrm{ng} / \mu \mathrm{l})$ were spotted in triplicate on to glass slides (FullMoon Biosystem) coated with polylysine, following the standard protocol developed by $\mathrm{P}$. Brown, Stanford, CA [65]. The DNA of the human $\beta$-actin gene and 50\% DMSO were included in the microarray design as internal control elements. The spotter and software used were from GeneMachines (Omnigrid and Gridder 2.0).

\section{Microarray, labeling and hybridization}

The genomic DNA of $L$. interrogans serovar Lai strain Lai was used as reference DNA in a double-fluorescence hybridization. Genomic DNAs from the reference strain 
Lai and other test strains were sonicated to fragments, ranging from $250 \mathrm{bp}$ to $2000 \mathrm{bp}$ in lengths. These DNA fragments were used as templates for the direct incorporation of fluorescent nucleotide analogs (Cy3- and Cy5dCTP respectively) (Amersham Biosciences Co.) by a randomly-primed polymerization reaction. In brief, $3 \mu \mathrm{g}$ of genomic DNA was labeled with $6 \mu \mathrm{g}$ of random nonamers (Takara), $25 \mathrm{U}$ of the Klenow fragment (New BioLab) and $1 \mathrm{nmol}$ of Cy3- or Cy5-dCTP at $37^{\circ} \mathrm{C}$ for $3 \mathrm{~h}$. Probes were purified by a QIAquick Nucleotide Removal Kit according to the manufacturer's instructions (Qiagen). Purified DNA probes were dried and finally resuspended in $8 \mu \mathrm{l}$ of sterilized distilled water. The labeled DNA sample was combined with $20 \mu \mathrm{l}$ formamide, $7.5 \mu \mathrm{l} 20 \times$ SSC, $0.3 \mu \mathrm{l}$ 10\% SDS, $1 \mu \mathrm{l} 10 \mathrm{mg} / \mathrm{ml}$ salmon sperm DNA (Life Technologies), denatured for $3 \mathrm{~min}$ at $99^{\circ} \mathrm{C}$, and applied to the microarray slide, which was then covered with a $24 \times$ $50 \mathrm{~mm}$ glass coverslip. The labeled DNA was hybridized to the DNA microarray in a hybridization chamber at $42^{\circ} \mathrm{C}$ for $16 \mathrm{~h}$. When the hybridization was complete, the slides were washed at $55^{\circ} \mathrm{C}$ with $1 \times$ SSC containing $0.2 \%$ SDS for $10 \mathrm{~min}$ and then at $55^{\circ} \mathrm{C}$ with $0.1 \times$ SSC containing $0.2 \%$ SDS for $20 \mathrm{~min}$, and finally at room temperature with $0.1 \times$ SSC for $3 \mathrm{~min}$. The last step was conducted twice. The slides were immediately dried and scanned for fluorescence intensity using a GenePix 4000B microarray scanner (Axon Instruments), and the results were recorded in 16-bit multi-image TIFF files. Competitive hybridization was conducted twice for each strain. In the first experiment, the strain Lai reference DNA and the sample DNA were labeled with Cy3 and Cy5, respectively. In the second hybridization, the dyes for labeling were interchanged.

\section{Data analysis}

The signal intensity of each spot in the microarray was quantified using GenePix Pro 4.0 (Axon Instruments) software. Additional data analyses were conducted by the computer software programs Microsoft Excel and GeneSpring 5.0.2 (Silicon Genetics). The data were filtered so that spots with the reference (strain Lai) signal lower than background plus 2 standard deviations of background were discarded. Signal intensities were corrected by subtracting the local background. Sample/reference (S/R) ratios of signal intensity were calculated and were transformed to logarithm base 2 . The ratios were normalized by taking the median $\log _{2}$ ratios of all spots as 0 . To determine the final value for each CDS tested, the median value was calculated from three $\log _{2}$ ratios obtained from 1 DNA microarray slide. In addition, to ensure only high quality data were used for analysis, spots that gave invalid results in one strain tested were considered as invalid results in other tests and thus, discarded. This allowed for the retrieval of 3,192 spots. CDSs were considered absent/ divergent if the final ratios of signal intensities were both less than -1.585 on the $\log _{2}$ scale in two dye-interchange experiments.

\section{Genomic comparison of the $L$. interrogans serovar Lai and $\mathbf{L}$. interrogans serovar Copenhageni strains in silico} Each nucleotide sequence of the CDSs assigned in the genome of strain L. interrogans serovar Lai (accession

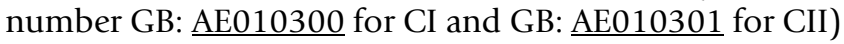
was used as a query for a homology search with BLASTN against the genome sequence of the $L$. interrogans serovar Copenhageni (accession number AE016823, AE016824). The region with the highest score for each query was retrieved and classified by the $H$ value. This homology score was proposed by Fukiya et al. [66] and reflects the degree of similarity between the matching test genome sequence and the probe itself in terms of the length of match and the percentage sequence identity at the DNA level. For each query, the $H$ value was calculated as follows: [(length of highest-score region) $\times$ (identities of hit shown in BLASTN)]/(length of query sequence). If there was no sequence with a BLASTN E value less than 0.01, the query CDS was judged to be absent from the L. interrogans serovarCopenhageni genome, and its $H$ value was 0 . Queries for genes that were probably absent gave low $\mathrm{H}$ values. Therefore, $H$ belonged to the set $[0,1]$. The $H$ value indicated how closely the corresponding sequence of $L$. interrogans serovar Copenhageni resembled the L. interrogans serovar Lai query CDS in terms of length and sequence identity.

\section{PCR validation}

Sixteen genes were randomly chosen from strain-specific genes to verify the CGH results. Primer sequences are in Additional file 3. For each gene, PCR was performed in 12 L. interrogans strains. The parameters for amplification were as follows: $95^{\circ} \mathrm{C}$ for $3 \mathrm{~min} ; 30$ cycles of $94^{\circ} \mathrm{C}$ for 30 sec, $55^{\circ} \mathrm{C}$ for $30 \mathrm{sec}$, and $72^{\circ} \mathrm{C}$ for $1 \mathrm{~min}$; and a final extension cycle of $72^{\circ} \mathrm{C}$ for $5 \mathrm{~min}$. PCR products were run on agarose gels to confirm the presence of a band of the expected size.

\section{Authors' contributions}

PH, YYS and XKG designed the research project. YYS and YZS constructed the microarray. PH, YYS and ZMZ completed the CGH. PH and JHQ carried out the data analysis. PH and XKG drafted the manuscript. XGJ and GPZ participated in the design of the study and helped to draft the manuscript. All authors contributed to the writing and preparation of the manuscript. All authors read and approved the final manuscript. 


\section{Additional material}

Additional file 1
CGH data file of L. interrogans.
Click here for file
[http://www.biomedcentral.com/content/supplementary/1471-
2164-8-204-S1.xls]
Additional file 2
Distribution of divergent genes encode surface-exposed proteins among the
strains tested.
Click here for file
[http://www.biomedcentral.com/content/supplementary/1471-
2164-8-204-S2.doc]
Additional file 3
Oligonucleotide primers used to confirm the CGH results.
Click here for file
[http://www.biomedcentral.com/content/supplementary/1471-
2164-8-204-S3.doc]

\section{Acknowledgements}

This work was supported in part by the grants from the National Natural Science Foundation of China (No. 3037007I \& 30670102), the National High Technology Research, Development Program of China and Shanghai Leading Academic Discipline Project (T0206), 985 project of Shanghai Jiao Tong University and 21 I project of Shanghai Jiao Tong University School of Medicine.

We are extremely grateful to Dr. Albert I. Ko (Fiocruz, Salvador, BA, Brazil) for kindly providing the genomic DNA of strain Fiocruz LI - I30. We also thank Bao-Yu Hu and Yang Yang (Shanghai Jiao Tong University School of Medicine, Shanghai, China) for help in bacterial culture preparation. Moreover, we are grateful to Dr. Picardeau. M (Unite de Bacteriologie Moleculaire et Medicale, Institut Pasteur Paries, France) and Dr. Yu-Feng Yao (Shanghai Jiao Tong University School of Medicine, Shanghai, China)for thoughtful comments on the manuscript preparation.

\section{References}

I. Levett PN: Leptospirosis. Clin Microbiol Rev 200I, I4(2):296-326.

2. Brenner DJ, Kaufmann AF, Sulzer KR, Steigerwalt AG, Rogers FC, Weyant RS: Further determination of DNA relatedness between serogroups and serovars in the family Leptospiraceae with a proposal for Leptospira alexanderi sp. nov. and four new Leptospira genomospecies. Int J Syst Bacteriol 1999, 49 Pt 2:839-858.

3. Jain AP, Narang P, Dey S, Mendiratta DK, Solao V: Leptospirosis--a case report. Indian J Pathol Microbiol 2003, 46(3):432-433.

4. Ramadass P, Jarvis BD, Corner RJ, Penny D, Marshall RB: Genetic characterization of pathogenic Leptospira species by DNA hybridization. Int J Syst Bacteriol 1992, 42(2):215-219.

5. Yasuda PH, Steigerwalt AG, Sulzer KR, Kaufmann AF, Rogers FC, Brenner DJ: Deoxyribonucleic acid relatedness between serogroups and serovars in the family Leptospiraceae with proposals for seven new leptospira species. Int J Syst Bacteriol 1987, 37:407-4I5.

6. Faine S, Adler B, Bolin C, Perolat P: Leptospira and leptospirosis, 2nd ed. Melbourne, Australia , MediSci; 1999.

7. Yu. ES, Luo. HB, Bao. XH, Dai. BM: leptospirosis. Second edition. Beijing , People's Medical Publishing House; 1992.

8. Ren SX, Fu G, Jiang XG, Zeng R, Miao YG, Xu H, Zhang YX, Xiong $H$, Lu G, Lu LF, Jiang HQ, Jia J, Tu YF, Jiang JX, Gu WY, Zhang YQ, Cai Z, Sheng HH, Yin HF, Zhang Y, Zhu GF, Wan M, Huang HL, Qian
Z, Wang SY, Ma W, Yao Z], Shen Y, Qiang BQ, Xia QC, Guo XK, Danchin A, Saint Girons I, Somerville RL, Wen YM, Shi MH, Chen Z, Xu JG, Zhao GP: Unique physiological and pathogenic features of Leptospira interrogans revealed by whole-genome sequencing. Nature 2003, 422(6934):888-893.

9. Nascimento AL, Verjovski-Almeida S, Van Sluys MA, MonteiroVitorello CB, Camargo LE, Digiampietri LA, Harstkeerl RA, Ho PL, Marques MV, Oliveira MC, Setubal JC, Haake DA, Martins EA: Genome features of Leptospira interrogans serovar Copenhageni. Braz J Med Biol Res 2004, 37(4):459-477.

10. Nascimento AL, Ko Al, Martins EA, Monteiro-Vitorello CB, Ho PL, Haake DA, Verjovski-Almeida S, Hartskeerl RA, Marques MV, Oliveira MC, Menck CF, Leite LC, Carrer H, Coutinho LL, Degrave WM, Dellagostin OA, El-Dorry H, Ferro ES, Ferro MI, Furlan LR, Gamberini M, Giglioti EA, Goes-Neto A, Goldman GH, Goldman MH, Harakava R, Jeronimo SM, Junqueira-de-Azevedo IL, Kimura ET, Kuramae EE, Lemos EG, Lemos MV, Marino CL, Nunes LR, de Oliveira RC, Pereira GG, Reis MS, Schriefer A, Siqueira WJ, Sommer P, Tsai SM, Simpson AJ, Ferro JA, Camargo LE, Kitajima JP, Setubal JC, Van Sluys MA: Comparative genomics of two Leptospira interrogans serovars reveals novel insights into physiology and pathogenesis. J Bacteriol 2004, I 86(7):2 I 64-2I72.

II. Bjorkholm B, Lundin A, Sillen A, Guillemin K, Salama N, Rubio C, Gordon JI, Falk P, Engstrand L: Comparison of genetic divergence and fitness between two subclones of Helicobacter pylori. Infect Immun 200 I, 69(I 2):7832-7838.

12. Chan K, Baker S, Kim CC, Detweiler CS, Dougan G, Falkow S: Genomic comparison of Salmonella enterica serovars and Salmonella bongori by use of an S. enterica serovar typhimurium DNA microarray. J Bacteriol 2003, I 85(2):553-563.

13. Porwollik S, Boyd EF, Choy C, Cheng P, Florea L, Proctor E, McClelland $M$ : Characterization of Salmonella enterica subspecies I genovars by use of microarrays. J Bacteriol 2004, I 86( I 7):5883-5898.

14. Porwollik S, Wong RM, McClelland M: Evolutionary genomics of Salmonella: gene acquisitions revealed by microarray analysis. Proc Natl Acad Sci U S A 2002, 99( I3):8956-896 I.

15. Salama N, Guillemin K, McDaniel TK, Sherlock G, Tompkins L, Falkow S: A whole-genome microarray reveals genetic diversity among Helicobacter pylori strains. Proc Natl Acad Sci U S A 2000, 97(26): | 4668-|4673.

16. de la Pena-Moctezuma A, Bulach DM, Adler B: Genetic differences among the LPS biosynthetic loci of serovars of Leptospira interrogans and Leptospira borgpetersenii. FEMS Immunol Med Microbiol 200I, 3 I (I):73-8I.

17. Saint Girons I, Margarita D, Amouriaux P, Baranton G: First isolation of bacteriophages for a spirochaete: potential genetic tools for Leptospira. Res Microbiol 1990, I 4 I (9): I I 3 I- I I 38.

18. Ralph D, McClelland M: Phylogenetic evidence for horizontal transfer of an intervening sequence between species in a spirochete genus. J Bacteriol 1994, I 76( I 9):5982-5987.

19. Kalambaheti T, Bulach DM, Rajakumar K, Adler B: Genetic organization of the lipopolysaccharide O-antigen biosynthetic locus of Leptospira borgpetersenii serovar Hardjobovis. Microb Pathog 1999, 27(2): I05-I I7.

20. Mitchison M, Bulach DM, Vinh T, Rajakumar K, Faine S, Adler B: Identification and characterization of the dTDP-rhamnose biosynthesis and transfer genes of the lipopolysacchariderelated rfb locus in Leptospira interrogans serovar Copenhageni. J Bacteriol 1997, I79(4): | 262-1267.

21. Karlin S: Detecting anomalous gene clusters and pathogenicity islands in diverse bacterial genomes. Trends Microbiol $200 \mathrm{I}$, 9(7):335-343.

22. Dobrindt $U$, Hochhut $B$, Hentschel $U$, Hacker J: Genomic islands in pathogenic and environmental microorganisms. Nat Rev Microbiol 2004, 2(5):4 I4-424.

23. Schmidt $\mathrm{H}$, Hensel M: Pathogenicity islands in bacterial pathogenesis. Clin Microbiol Rev 2004, I 7(I): 14-56.

24. Kajava AV: Structural diversity of leucine-rich repeat proteins. J Mol Biol I998, 277(3):519-527.

25. Machner MP, Frese S, Schubert WD, Orian-Rousseau V, Gherardi E, Wehland J, Niemann HH, Heinz DW: Aromatic amino acids at the surface of InIB are essential for host cell invasion by Listeria monocytogenes. Mol Microbiol 2003, 48(6): I 525-I 536.

26. Reid SD, Montgomery AG, Voyich JM, DeLeo FR, Lei B, Ireland RM, Green NM, Liu M, Lukomski S, Musser JM: Characterization of an 
extracellular virulence factor made by group A Streptococcus with homology to the Listeria monocytogenes internalin family of proteins. Infect Immun 2003, 7 I (I 2):7043-7052.

27. Evdokimov AG, Anderson DE, Routzahn KM, Waugh DS: Unusual molecular architecture of the Yersinia pestis cytotoxin YopM: a leucine-rich repeat protein with the shortest repeating unit. J Mol Biol 200I, 3 I 2(4):807-82I.

28. Miao EA, Scherer CA, Tsolis RM, Kingsley RA, Adams LG, Baumler A], Miller SI: Salmonella typhimurium leucine-rich repeat proteins are targeted to the SPII and SPI2 type III secretion systems. Mol Microbiol 1999, 34(4):850-864.

29. Hartman AB, Venkatesan M, Oaks EV, Buysse JM: Sequence and molecular characterization of a multicopy invasion plasmid antigen gene, ipaH, of Shigella flexneri. J Bacteriol 1990, I72(4): $1905-1915$.

30. Torres AG, Payne SM: Haem iron-transport system in enterohaemorrhagic Escherichia coli OI57:H7. Mol Microbiol 1997, 23(4):825-833.

3I. Stojiljkovic I, Hantke K: Hemin uptake system of Yersinia enterocolitica: similarities with other TonB-dependent systems in gram-negative bacteria. Embo J 1992, I I (12):4359-4367.

32. Mills M, Payne SM: Identification of shuA, the gene encoding the heme receptor of Shigella dysenteriae, and analysis of invasion and intracellular multiplication of a shuA mutant Infect Immun I 997, 65( ( 2):5358-5363.

33. Ren Z, Jin H, Morton DJ, Stull TL: hgpB, a gene encoding a second Haemophilus influenzae hemoglobin- and hemoglobin-haptoglobin-binding protein. Infect Immun 1998, 66(10):4733-474I.

34. Torres AG, Redford P, Welch RA, Payne SM: TonB-dependent systems of uropathogenic Escherichia coli: aerobactin and heme transport and TonB are required for virulence in the mouse. Infect Immun 200I, 69(10):6179-6I85.

35. Nagy G, Dobrindt U, Kupfer M, Emody L, Karch H, Hacker J: Expression of hemin receptor molecule ChuA is influenced by $\mathrm{RfaH}$ in uropathogenic Escherichia coli strain 536. Infect Immun 2001, 69(3): 1924-1928.

36. Lee SH, Kim KA, Park YG, Seong IW, Kim MJ, Lee YJ: Identification and partial characterization of a novel hemolysin from Leptospira interrogans serovar lai. Gene 2000, 254(I-2): 19-28.

37. Zhang YX, Geng Y, Bi B, He JY, Wu CF, Guo XK, Zhao GP: Identification and classification of all potential hemolysin encoding genes and their products from Leptospira interrogans serogroup Icterohae-morrhagiae serovar Lai. Acta Pharmacol Sin 2005, 26(4):453-46I.

38. Bourhy P, Salaun L, Lajus A, Medigue C, Boursaux-Eude C, Picardeau $M$ : A genomic island of the pathogen Leptospira interrogans serovar Lai can excise from its chromosome. Infect Immun 2006.

39. Tobin JF, Schleif RF: Purification and properties of RhaR, the positive regulator of the L-rhamnose operons of Escherichia coli. J Mol Biol 1990, 2 I I ( I):75-89.

40. Caron J, Coffield LM, Scott JR: A plasmid-encoded regulatory gene, rns, required for expression of the CSI and CS2 adhesins of enterotoxigenic Escherichia coli. Proc Natl Acad Sci U S A 1989, 86(3):963-967.

4I. de Haan LA, Willshaw GA, van der Zeijst BA, Gaastra W: The nucleotide sequence of a regulatory gene present on a plasmid in an enterotoxigenic Escherichia coli strain of serotype O167:H5. FEMS Microbiol Lett 1991, 67(3):341-346.

42. Frank DW, Iglewski BH: Cloning and sequence analysis of a trans-regulatory locus required for exoenzyme $\mathbf{S}$ synthesis in Pseudomonas aeruginosa. | Bacteriol |99|, | 73(20):6460-6468.

43. Hakura A, Morimoto K, Sofuni T, Nohmi T: Cloning and characterization of the Salmonella typhimurium ada gene, which encodes O6-methylguanine-DNA methyltransferase. J Bacteriol I99I, I 73(I 2):3663-3672.

44. Jost BH, Adler B, Vinh T, Faine S: A monoclonal antibody reacting with a determinant on leptospiral lipopolysaccharide protects guinea pigs against leptospirosis. J Med Microbiol 1986 22(3):269-275.

45. Chapman AJ, Adler B, Faine S: Antigens recognised by the human immune response to infection with Leptospira interrogans serovar hardjo. J Med Microbiol I 988, 25(4):269-278.

46. de la Pena-Moctezuma A, Bulach DM, Kalambaheti T, Adler B: Comparative analysis of the LPS biosynthetic loci of the genetic subtypes of serovar Hardjo: Leptospira interrogans subtype
Hardjoprajitno and Leptospira borgpetersenii subtype Hardjobovis. FEMS Microbiol Lett 1999, I77(2):319-326.

47. Koizumi N, Watanabe $\mathrm{H}$ : Leptospirosis vaccines: past, present, and future. J Postgrad Med 2005, 5 I (3):2 I 0-2 I4

48. Yan Y, Chen Y, Liou W, Ding J, Chen J, Zhang J, Zhang A, Zhou W, Gao Z, Ye X, Xiao Y: An evaluation of the serological and epidemiological effects of the outer envelope vaccine to leptospira. J Chin Med Assoc 2003, 66(4):224-230.

49. Guerreiro H, Croda J, Flannery B, Mazel M, Matsunaga J, Galvao Reis M, Levett PN, Ko Al, Haake DA: Leptospiral proteins recognized during the humoral immune response to leptospirosis in humans. Infect Immun 200I, 69(8):4958-4968.

50. Sonrier C, Branger C, Michel V, Ruvoen-Clouet N, Ganiere JP, AndreFontaine G: Evidence of cross-protection within Leptospira interrogans in an experimental model. Vaccine 2000 , 19(I):86-94.

5I. Cullen PA, Haake DA, Bulach DM, Zuerner RL, Adler B: LipL2I is a novel surface-exposed lipoprotein of pathogenic Leptospira species. Infect Immun 2003, 7 I(5):24I4-242I.

52. Haake DA, Champion $\mathrm{Cl}$, Martinich $\mathrm{C}$, Shang ES, Blanco DR, Miller $J N$, Lovett MA: Molecular cloning and sequence analysis of the gene encoding OmpLI, a transmembrane outer membrane protein of pathogenic Leptospira spp. J Bacteriol 1993, 175(I3):4225-4234.

53. Haake DA, Chao G, Zuerner RL, Barnett JK, Barnett D, Mazel M, Matsunaga J, Levett PN, Bolin CA: The leptospiral major outer membrane protein LipL32 is a lipoprotein expressed during mammalian infection. Infect Immun 2000, 68(4):2276-2285.

54. Matsunaga J, Barocchi MA, Croda J, Young TA, Sanchez Y, Siqueira I, Bolin CA, Reis MG, Riley LW, Haake DA, Ko Al: Pathogenic Leptospira species express surface-exposed proteins belonging to the bacterial immunoglobulin superfamily. Mol Microbiol 2003, 49(4):929-945

55. Matsunaga J, Young TA, Barnett JK, Barnett D, Bolin CA, Haake DA Novel 45-kilodalton leptospiral protein that is processed to a 3I-kilodalton growth-phase-regulated peripheral membrane protein. Infect Immun 2002, 70(I):323-334.

56. Yang $\mathrm{HL}$, Zhu YZ, Qin JH, He P, Jiang XC, Zhao GP, Guo XK: In silico and microarray-based genomic approaches to identifying potential vaccine candidates against Leptospira interrogans. BMC Genomics 2006, 7:293.

57. Zhang XY, Yu Y, He P, Zhang YX, Hu BY, Yang Y, Nie YX, jiang XG, Zhao GP, Guo XK: Expression and comparative analysis of genes encoding outer membrane proteins LipL21, LipL32 and OmpLI in epidemic leptospires. Acta Biochim Biophys Sin (Shanghai) 2005, 37(10):649-656

58. Koizumi N, Watanabe H: Leptospiral immunoglobulin-like proteins elicit protective immunity. Vaccine 2004, 22(I I12): I545-I552.

59. Haake DA, Mazel MK, McCoy AM, Milward F, Chao G, Matsunaga J, Wagar EA: Leptospiral outer membrane proteins OmpLI and LipL4I exhibit synergistic immunoprotection. Infect Immun 1999, 67( I 2):6572-6582.

60. Branger C, Sonrier C, Chatrenet B, Klonjkowski B, Ruvoen-Clouet N, Aubert A, Andre-Fontaine G, Eloit M: Identification of the hemolysis-associated protein $I$ as a cross-protective immunogen of Leptospira interrogans by adenovirus-mediated vaccination. Infect Immun 200 I, 69(I I):683 I-6838

61. Mosavi LK, Cammett T], Desrosiers DC, Peng ZY: The ankyrin repeat as molecular architecture for protein recognition. Protein Sci 2004, I3(6): | 435-1448.

62. Caturegli P, Asanovich KM, Walls JJ, Bakken JS, Madigan JE, Popov VL, Dumler JS: ankA: an Ehrlichia phagocytophila group gene encoding a cytoplasmic protein antigen with ankyrin repeats. Infect Immun 2000, 68(9):5277-5283.

63. Howell ML, Alsabbagh E, Ma JF, Ochsner UA, Klotz MG, Beveridge T], Blumenthal KM, Niederhoffer EC, Morris RE, Needham D, Dean GE, Wani MA, Hassett DJ: AnkB, a periplasmic ankyrin-like protein in Pseudomonas aeruginosa, is required for optimal catalase $B$ (KatB) activity and resistance to hydrogen peroxide. J Bacteriol 2000, I 82(16):4545-4556.

64. Johnson RC, Walby J, Henry RA, Auran NE: Cultivation of parasitic leptospires: effect of pyruvate. Appl Microbiol 1973 , 26(1): I I8-119.

65. Pollack JR, Perou CM, Alizadeh AA, Eisen MB, Pergamenschikov A Williams CF, Jeffrey SS, Botstein D, Brown PO: Genome-wide 
analysis of DNA copy-number changes using cDNA microarrays. Nat Genet 1999, 23(1):4I-46.

66. Fukiya S, Mizoguchi H, Tobe T, Mori H: Extensive genomic diversity in pathogenic Escherichia coli and Shigella Strains revealed by comparative genomic hybridization microarray. J Bacteriol 2004, I 86( ( 2):39||-3921.

67. Clusters of Orthologous Groups [http://www.ncbi.nlm.nih.gov/ entrez/]

Publish with Bio Med Central and every scientist can read your work free of charge

"BioMed Central will be the most significant development for disseminating the results of biomedical research in our lifetime. " Sir Paul Nurse, Cancer Research UK

Your research papers will be:

- available free of charge to the entire biomedical community

- peer reviewed and published immediately upon acceptance

- cited in PubMed and archived on PubMed Central

- yours - you keep the copyright

Submit your manuscript here:

http://www.biomedcentral.com/info/publishing_adv.asp
BioMedcentral 